\title{
The New Structural Design for Airborne Pod
}

\author{
Dongfang $\mathrm{Hu}^{1, \mathrm{a}^{*}}$, Jianwei Guo ${ }^{1, \mathrm{~b}}$ and Yan Zhao ${ }^{2, \mathrm{c}}$
}

${ }^{1}$ School of Mechatronics Engineering, Henan University of Science and Technology, Luoyang 471003, China

\author{
${ }^{2}$ LandGlass Technology Co., Ltd, Luoyang 471003, China \\ ahdf@haust.edu.cn, bguojianwei1991@yeah.net, ’hlxc-2009@163.com
}

Keywords: Airborne pod; Horizontal shafting; Vertical shafting; Design system

\begin{abstract}
Airborne pod is mounted on helicopters or unmanned aerial vehicles. Its main structure tends to be influenced by many factors such as air flow, air temperature, foreign body, and the normal work of sensors may be interfered. However, a logical mechanical system's structure can effectively improve the imaging effect and improve the scanning accuracy. Thus, through systematically elaborate the arrangement of its control system, the theory for dividing horizontal shafting and vertical shafting, and the method for outputting completed 3D models and their supporting engineering drawings by UG platform, a composite structure of airborne pod is designed, which provides a preliminary design system for domestic new airborne pod structure.
\end{abstract}

\section{Introduction}

The pod adopts the axially symmetric structure to improve the overall strength of the pod, and build the "two axis and two frame" structure which realizes the operation on economy and high efficiency $[1,2]$.

On the basis of the above given technical indicators, the design for pod body is divided into two part - the part of frames and the part of motion mechanism.

The part of motion mechanism refers to the horizontal axis organization and the azimuth axis organization. The horizontal axis organization controls the cabin changing the pitch angle of the implementation, which achieves the pitching motion of the inner framework; the holder linked with the azimuth axis as a whole, is mainly used to achieve the azimuth rotation of the outer shell. The whole machine uses the upper part of the pod to link with the bottom plate of the plane [2]. The layout structure of the air-borne pod is as shown in Fig. 1.

\section{The Specific Layout Structure of Airborne Pod}

The Shaft Arrangement of the Airborne Pod. The horizontal axis and its drive system, arms of the holder and the main frame, are named as the horizontal shafting; meanwhile, the azimuth axis and its drive system, the upper arm of the holder, the upper body of the whole pod, are called as the azimuth shafting. Horizontal shaft design will be discussed in detail

Moreover, the control system of scanning objects and the control system of internal environment are designed to improve the safe operation of the system, we adopt the frame structure of symmetry which could make the pod's the center of gravity and its geometric center overlap together, this structure will greatly limit the impact resistance from flying posture and reduce from the perspective of the difficulty of adjustment $[3,4]$.

The Main Framework Design of the Airborne Pod. Taking into account that kinds of internal photoelectric instruments need avoid the influence of temperature [5, 6], we design a kind of servo system concluding temperature compensation and motion control, its specific layout is as shown in Fig. 2 . 


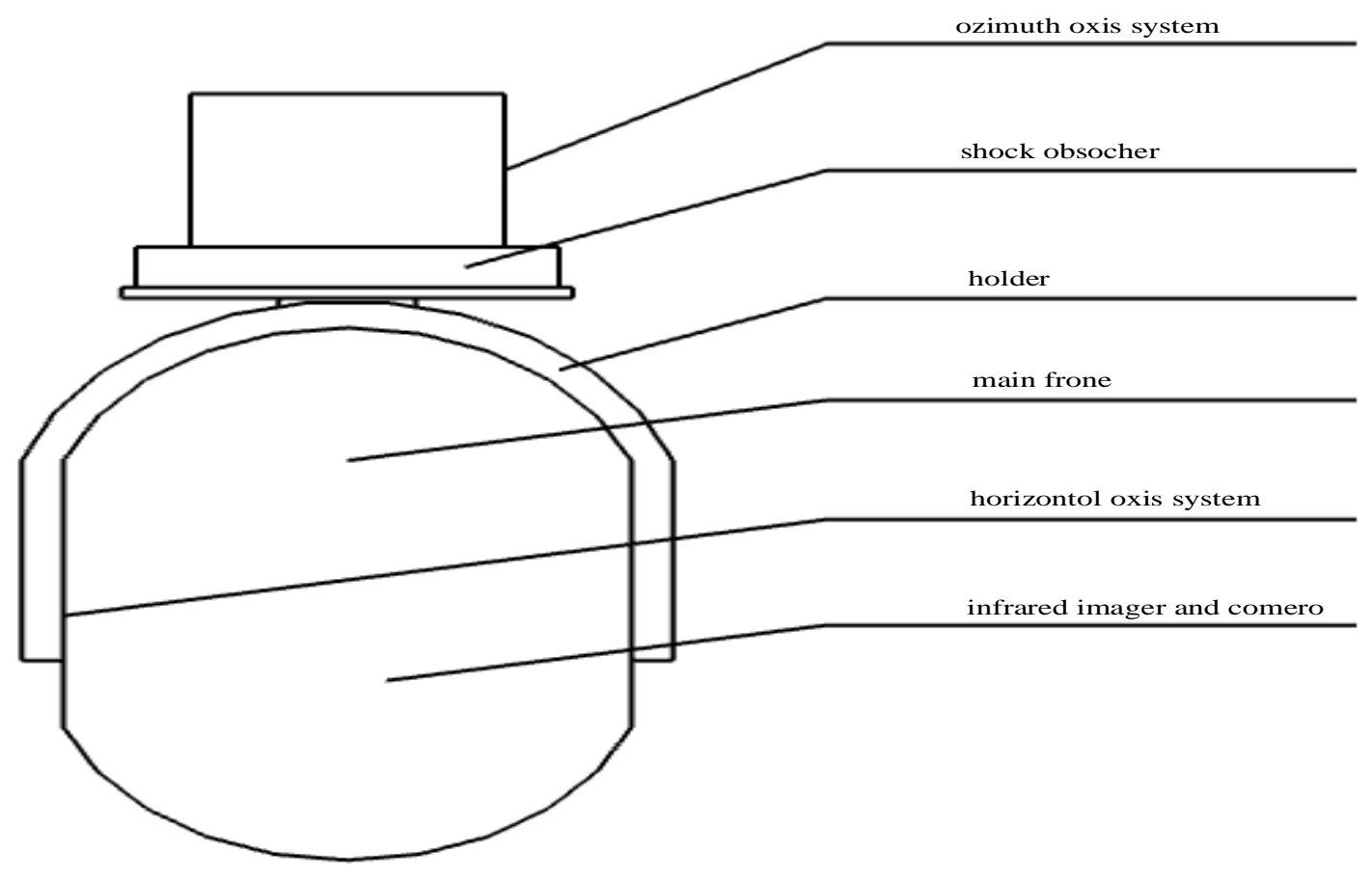

Figure 1. The structural layout of the airborne pod

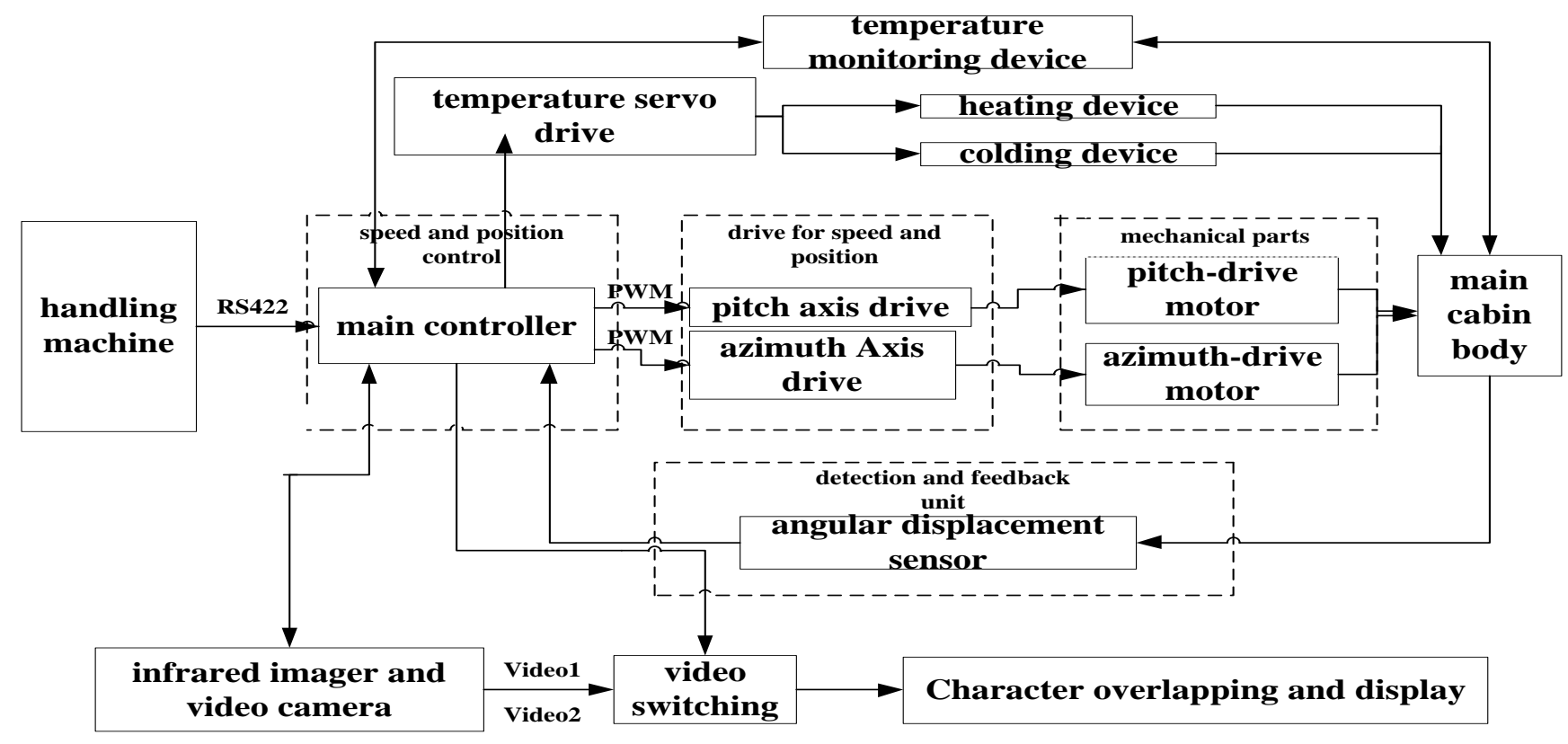

Figure 2. The servo system for thermal compensation and motion control.

\section{The Horizontal Shafting Structural Design of the Pod}

The selection of the motor is the key in the electric drive system. According to the design requirements: high speed, large torque, high running accuracy, and the working environment of low temperature, a Swiss series of cryogenic permanent magnet DC servo motor is our preliminary choice.

The Components Selection and the Corresponding Load in the Horizontal Shafting. Tab According to the design requirements, the outer shell is designed as the structure which composed of the front shell and the back shell, and its diameter is $260 \mathrm{~mm}$. 
In addition, we have made ABS-GF shell material for the machine of the infrared imaging and visible light camera.

All of the parts are divided into the two types-the mechanical parts and the electrical load Calculation of the moment of inertia, and the software UG was used after the assembly, the details as shown in Table 1.

The Assembly Parameters of the Horizontal Drive Shaft. Simplify the problem to a reducer gear. The effective power of the horizontal shaft work as required.

$$
P_{w}=F_{v}=2.0415
$$

According to the mechanical design manual, the motor output power to meet the requirement [7].

$$
P_{1}=\frac{P_{w}}{\eta_{1} \times \eta_{2} \times \eta_{3}}=2.1693 w
$$

\begin{tabular}{|c|c|c|c|c|}
\hline \multirow[t]{2}{*}{ Category } & \multirow[t]{2}{*}{ Item } & \multicolumn{3}{|c|}{ Results of UG analysis } \\
\hline & & shop sign & quality/kg & inertia $/ \mathrm{kg} \bullet \mathrm{m}^{2}$ \\
\hline \multirow{10}{*}{$\begin{array}{l}\text { Mechanical } \\
\text { structure }\end{array}$} & sealing material & 5171 & 0.0018 & $2.5922 \times 10^{-5}$ \\
\hline & front shell & ZL205A & 0.4199 & 0.0048 \\
\hline & back shell & ZL205A & 1.2972 & 0.0118 \\
\hline & $\begin{array}{l}\text { hot and cold } \\
\text { temperature } \\
\text { controller }\end{array}$ & LHS_15 & 0.0813 & 0.0009 \\
\hline & bearing frame & ZL205A & 0.3652 & 0.0014 \\
\hline & $\begin{array}{c}\text { vibration } \\
\text { damper plate }\end{array}$ & $2 \mathrm{~A} 12$ & 0.1625 & 0.0002 \\
\hline & Gear 1a, 1b & $40 \mathrm{CrA}$ & 0.2859 & 0.0007 \\
\hline & spoiler motor & MONO & 0.1444 & 0.0008 \\
\hline & $\begin{array}{l}\text { angle measuring } \\
\text { device }\end{array}$ & M2500 & 0.1188 & $2.3196 \times 10^{-5}$ \\
\hline & $\begin{array}{c}\text { other } \\
\text { connections }\end{array}$ & Alloy steel & 0.1994 & 0.0016 \\
\hline \multirow[t]{2}{*}{ Electrical load } & Infrared imager & l & 0.7800 & 0.0041 \\
\hline & camera & / & 0.4500 & \\
\hline
\end{tabular}

Table 1 The inertia estimating form for the horizontal shaft's main parts

According to the motor has been selected, the out-put power is $62 \mathrm{w}$ which is much higher than the actual needs of the power, so it can meet the requirements.

$$
i=\frac{n_{m}}{n_{w}}
$$

In the formula, $\mathrm{i}$ is the total transmission ratio, $\mathrm{nm}$ is the full speed reducer of the DC motor, and its value is $20.9790 \mathrm{r} / \mathrm{min}$. The output power of DC motor with gear output to the outer frame

$$
n_{w}=\frac{60 v}{\pi d_{i}}=123.2033 \mathrm{r} / \mathrm{min}
$$

It is concluded: $\mathrm{i}=1.7191$, due to its transmission is only one level, so the gear ratio is $i 01=1.719$

The Design for the Shaft, Bearings, the Key of the Horizontal Shafting. Calculation criterion of shaft can be divided into strength checking and axial stiffness checking. When the shaft is used with high-speed rotation, the shaft vibration checking should be carried out.

The Drive Shaft I. The shaft power P1=61.38w, n1=20.9790r $/ \mathrm{min}$, the torque T1 is $27.9412 \mathrm{~N} \cdot \mathrm{m}$. The force on the shaft of the gear 1a. 


$$
\begin{aligned}
& F_{t}=\frac{2 T_{1}}{d_{1}}=\frac{2 \times 27.9412 \times 10^{3}}{50}=1117.648 \mathrm{~N} \\
& F_{r}=F_{t} \tan \alpha=1117.648 \times \tan 20^{\circ}=406.791 \mathrm{~N} \\
& F_{n}=\frac{F_{t}}{\cos \alpha}=\frac{1117.648}{\cos 20^{\circ}}=1189.376 \mathrm{~N}
\end{aligned}
$$

According to the technical parameters given by enterprises, to determine the minimum diameter of the initial axis, selected the shaft material is $40 \mathrm{Cr}$ which makes the quenching and tempering treatment. Taking $\mathrm{A} 0=97$, then giving the following data.

$$
d_{\min }=A_{0} \sqrt[3]{\frac{P_{1}}{n_{1}}}=97 \times 0.1430=13.8735 \mathrm{~mm}
$$

The minimum diameter of the shaft is in accordance with the diameter of the shaft coupling mechanism to select. In this design, we use four connecting bolts install the pitch-drive motor at the inner frame, and the motor shaft and gear 1a are be fixed as a whole by the small key. The inner six angle screw bolt is arranged in the hole of the convex side of the gear 1a, it presses the key to prevent small loose. The gear 1a and the motor shaft directly use a flat wedge key to position their location; the motor shaft diameter is $14 \mathrm{~mm}$. the data of motor diameter can be checked the key width $\mathrm{b}$ and the key height, it is $5 \times 5 \mathrm{~mm}$. the key length $\mathrm{L}$ is $16 \mathrm{~mm}$.

In order to improve the running reliability of the system, a set screw. At the same time, in order to ensure the gear with the shaft of the motor having a good selection of neutral, the gear wheel and the shaft of the motor should put to use H7/n6.

For the axial force analysis and the calculation of bending moment, considering the paper has said, we simplify the problem as the sake of cantilever beam bending moment and shear force. Among them, the distance between the sustain device of the motor and the gear center is $\mathrm{L} 1=8 \mathrm{~mm}$.

$$
\begin{aligned}
& F_{N H}=\frac{F_{t} \cdot L_{1}}{L_{1}}=1117.648 \mathrm{~N} \\
& F_{N V}=\frac{F_{r} \cdot L_{1}}{L_{1}}=406.791 \mathrm{~N} \\
& F_{N}=\sqrt{F_{N H}^{2}+F_{N V}^{2}}=1189.376 \mathrm{~N} \\
& M_{N H}=F_{N H} \cdot L_{1}=1117.648 \times 0.008=8.941 \mathrm{~N} \cdot \mathrm{m} \\
& M_{N V}=F_{N V} \cdot L_{1}=406.791 \times 0.008=3.254 \mathrm{~N} \cdot \mathrm{m} \\
& M=\sqrt{M_{N H}^{2}+M_{N V}^{2}}=\sqrt{79.941+10.589}=9.515 \mathrm{~N} \cdot \mathrm{m} \\
& T=T_{1}=27.9412 \mathrm{~N} \cdot \mathrm{m}
\end{aligned}
$$

The result, $\sigma_{\mathrm{p}}=99.79 \mathrm{MPa}$.

Checking tables $\left[\sigma_{\mathrm{P}}\right]=100 \sim 120 \mathrm{MPa}$, clearly meet the requirements.

Strength check of shaft.

According to the checking of bending and torsional strength calculation, we check the root section of the axis of maximum bending moment and torsion shaft. 


$$
\begin{gathered}
\sigma_{c a}=\frac{\sqrt{M^{2}+(\alpha T)^{2}}}{W} \\
W=\frac{\pi d^{3}}{32}-\frac{b t(\mathrm{~d}-\mathrm{t})^{2}}{2 d}
\end{gathered}
$$

The shaft is unidirectional rotation, torsion shear stress is pulsating cyclic stress, $\alpha=0.6$.

$$
\sigma_{c a}=\frac{\sqrt{9515^{2}+(0.6 \times 27941.2)^{2}}}{330.9325}=58.2496 \mathrm{MPa}<\left[\sigma_{-1}\right]
$$

The shaft's strength meets the design standards.

According to the calculation of the shaft stiffness checking, we focused on the end of the shaft mounted gear 1a as the study object, the cantilever beam deflection and angle formula.

$$
\begin{aligned}
& w=\frac{-F x^{2}}{6 E I}(3 l-x) \\
& \theta=\frac{-F l^{2}}{2 E I}
\end{aligned}
$$

According to the known data, $\mathrm{FN}=1189.376 \mathrm{~N}$, the elastic modulus of $40 \mathrm{Cr}$ was $\mathrm{E}=210 \mathrm{GPa}$, $\mathrm{I}=\pi \mathrm{d} 4 / 64$, When the " $\mathrm{x}$ " is 1 , we get these result: $\mathrm{w}=5.1259 \times 10-10<<0.0021$, $\theta=9.6110 \times 10-11<<0.001$.

The Drive Shaft II (the Fixed Mandrel). The pod is designed for symmetry, in the analysis of II transmission shaft, the drive shaft support focus on the side of the detailed analysis and calculation, the assumption that the shaft is a drive shaft, the shaft power is $\mathrm{P} 2=59.5386 \mathrm{w}, \mathrm{n} 2=12.2042 \mathrm{r} / \mathrm{min}$, the torque is $\mathrm{T} 2=46.5900 \mathrm{~N} \cdot \mathrm{m}$. The minimum diameter of the initial axis, according to the technical parameters given by enterprises, selection of shaft material is $40 \mathrm{Cr}$, quenching and tempering treatment. $\mathrm{A} 0=97$.

$$
d_{\min }=A_{0} \sqrt[3]{\frac{P_{2}}{n_{2}}}=97 \times 0.1696=16.4512 \mathrm{~mm}
$$

\section{Summary}

The pod is adopted the symmetric structure. Meanwhile, the 'two axes and two frames' structure is proposed.

Introducing the design idea of the airborne pod structure, which provides strong evidence for the feasibility of pod.

The mechanism of control system is designed and operated from the aspects of control theory; the possible problems in the pod structure design had been made a detailed analysis.

Through the design of horizontal shaft system, and the calculation of each component's material selection, the whole structure design is completed by using UG solid modeling.

Due to the use of UG drawing module, the 3D design could directly switch into the 2D pictures used as figures, which greatly simplifies the design process and provide the safeguard for the manufacturing process.

\section{Acknowledgements}

The authors gratefully acknowledge the National Nature Science Foundation (Project No. 51575160), the Key Technology R \&D Program of Henan Province (Project No. 13A520232), and the Major and previous pre-research project of Henan University of Science and Technology (Project No. 2011CX016). 


\section{References}

[1] H.L. Ma: The structural design research and finite element analysis on two gimbals and two axis opto-electronic platform (MS., Jilin University, China 2011), p.3 (In Chinese).

[2] L.B. Wang: The application and research of con-trol system for airborne optoelectronic pod (MS., Henan University of Science and Technology, China 2011), p.2 (In Chinese).

[3] Y.F. Shen, P.Y. Zhao, and Z.J. Chen: Aero Weaponry, (2010) No.3, p.61 (In Chinese).

[4] M. Zhang, W.B. Liu, and C. Li: Acta Aeronautica ET Astronautica Sinica, Vol. 43 (2015) No.3, p.857 (In Chinese).

[5] Y.P. Qu: Acta Aeronautica et Astro-nautica Sinica, Vol. 35 (2014) No.8 p.2307 (In Chinese).

[6] J.Z. Yu, N. Su: Acta Aeronautica ET Astro-nautica Sinica, Vol. 21 (2000) No.5 p.399 (In Chinese).

[7] The editorial board for the handbook of me-chanical design: Machinerys Handbook. (China Machine Press, Beijing, 2004) (In Chinese). 